\title{
Rehun D-vitamiinipitoisuuden vaikutus munivien kanojen tuotantoon ja kuntoon
}

\author{
Eija Valkonen ${ }^{1)}$, Pirjo Mattila ${ }^{2)}$, Jarmo Valaja ${ }^{1)}$, Laila Rossow ${ }^{3)}$, Eija Venäläinen ${ }^{1)}$ ja Tuomo Tupasela $^{2)}$ \\ ${ }^{1)}$ MTT, Kotieläintuotannon tutkimus, Eläinravitsemus, 31600 Jokioinen, etunimi.sukunimi@mtt.fi \\ ${ }^{2}$ MTT, Elintarvikkeiden tutkimus, 31600 Jokioinen, etunimi.sukunimi@mtt.fi \\ ${ }^{3}$ Eläinlääkintä ja elintarviketutkimuslaitos, PL 45, 00581 Helsinki, etunimi.sukunimi@eela.fi
}

\begin{abstract}
Johdanto
D-vitamiinia saadaan ravinnosta ja auringon ultraviolettivalon vaikutuksesta iholla tapahtuvan synteesin tuloksena. Talvella D-vitamiinin ainoita lähteitä ovat elintarvikkeet ja vitamiinivalmisteet. Kananmuna on luonnostaan yksi ravinnon D-vitamiinilähteistä; keskimäärin $10 \%$ :a suomalaisen ravinnostaan saamasta D-vitamiinista on peräisin kanamunasta. D-vitamiinirikastetuille elintarvikkeille on ravitsemuksellinen tilaus Pohjois- ja Keski-Euroopassa, jossa auringon ultraviolettisäteily on vähäistä talvikuukausien aikana. Kananmunan D-vitamiinipitoisuus voidaan kohottaa halutulle tasolle lisäämällä D-vitamiinia kanojen rehuun (Mattila ym. 1999).

D-vitamiinimyrkytys voi aiheuttaa luuston suolojen takaisin imeytymistä ja kalsiumin epänormaalia kertymistä pehmytkudoksiin (Scott ym.1976). Tällä hetkellä korkein sallittu rehun D-vitamiinipitoisuus on $3000 \mathrm{ky} / \mathrm{kg}$. Lainsäädännön muutoksen hakua varten on selvitettävä D-vitamiinilisäyksen vaikutuksia munivien kanojen hyvinvointiin. Tässä tutkimuksessa D-vitamiinilisäysten vaikutuksia kanojen tuotantoon, kuntoon ja munan laatuun tutkittiin koko tuotantokauden ajan (48 viikkoa).
\end{abstract}

\section{Aineisto ja menetelmät}

Kokeessa oli mukana 450 LSL-kanaa, jotka kokeen alkaessa olivat 20 viikon ikäisiä. Kanat pidettiin perinteisissä kolmen kanan häkeissä $\left(640 \mathrm{~cm}^{2} /\right.$ kana) kaksikerroksisessa häkkipatterissa. Koeyksikön (kerranteen) muodosti kuuden vierekkäisen häkin rivi (18 kanaa). Kerranteet jaettiin satunnaisesti eri koekäsittelyille. Koekäsittelyjä oli viisi:

Ryhmä 1: normaali rehun $\mathrm{D}_{3}$-vitamiinipitoisuus $2500 \mathrm{ky} / \mathrm{kg}$ (kontrollikäsittely)

Ryhmä 2: $\mathrm{D}_{3}$-vitamiinia $6000 \mathrm{ky} / \mathrm{kg}$ rehua

Ryhmä 3: $\mathrm{D}_{3}$-vitamiinia $15000 \mathrm{ky} / \mathrm{kg}$ rehua

Ryhmä 4: $\mathrm{D}_{2}$-vitamiinia $6000 \mathrm{ky} / \mathrm{kg}$ rehua ja $\mathrm{D}_{3}$-vitamiinia $2500 \mathrm{ky} / \mathrm{kg}$

Ryhmä 5: $\mathrm{D}_{2}$-vitamiinia $15000 \mathrm{ky} / \mathrm{kg}$ rehua ja $\mathrm{D}_{3}$-vitamiinia $2500 \mathrm{ky} / \mathrm{kg}$

Ryhmien 4 ja 5 rehuihin lisättiin myös $\mathrm{D}_{3}$-vitamiinia, koska kanojen $\mathrm{D}_{2}$-vitamiinin hyväksikäyttökyky on heikko (Ameenuddin ym. 1985).

Ennen kokeen alkua kanat saivat vapaasti normaalia alkumunintarehua, jonka $\mathrm{D}_{3^{-}}$ vitamiinipitoisuus oli $2500 \mathrm{ky} / \mathrm{kg}$. Rehuraaka-aineina käytettiin soijarouhetta, ohraa, vehnää, kauraa, rypsiöljyä, ruokasuolaa, vitamiini- ja kivennäisesiseoksia sekä DL-metioniinia. Munintakausi jaettiin kolmeen ruokintavaiheeseen. Rehun energia- ja valkuaispitoisuudet laskivat vaiheittain munintakauden loppua kohden. Muuntokelpoisen energian määrä rehuissa eri ruokintavaiheiden aikana oli 10,7; 10,5 ja $10,4 \mathrm{MJ} / \mathrm{kg}$. Rehujen valkuaisenergiasuhde oli koko kokeen ajan 14,5 ja rehujen valkuaispitoisuus vastaavasti eri ruokintavaiheiden aikana $155,154 \mathrm{ja} 151 \mathrm{~g} / \mathrm{kg}$. Rehujen ravintoainepitoisuus vastasi NRC:n (1994) suosituksia muniville kanoille. Kanat saivat vapaasti rehua ja vettä koko kokeen ajan.

Koe jaettiin 12:een neljän viikon mittaiseen jaksoon. Rehunkulutus laskettiin kerranteittain kunkin jakson ajalta. Munantuotos kirjattiin joka päivä kerranteittain ja keskimääräinen tuotos laskettiin kutakin jaksoa kohden. Puolet linnuista punnittiin jokaisen rehuvaiheen alussa ja kokeen lopussa (20, 35, 51 ja 67 viikon iässä). Kymmenen munaa kutakin kerrannetta kohti kerättiin laatumääritystä varten kolme kertaa kokeen aikana $(35,51$ ja 67 viikon iässä). Laatumäärityksissä mitattiin kuoren murtolujuus, munan ominaispaino ja valkuaisen korkeus. Lisäksi kolmesta munasta kutakin kerrannetta kohti määritettiin kuoren kalsiumpitoisuus. Kokeen päätyttyä 20 kanaa jokaisesta käsittelystä lopetettiin. Puolet lopetetuista kanoista tutkittiin mahdollisten histo-patologisten muutosten löytämiseksi ja puolet käytettiin sääriluun murtolujuuden määritykseen.

Keltuaisten D-vitamiinipitoisuuksien määritystä varten kerättiin 20 munaa jokaisesta käsittelystä neljä kertaa kokeen aikana $(4,16,28$ ja 44 viikon kuluttua kokeen alkamisesta). Ryhmän 5 munien Dvitamiinipitoisuus määritettiin lisäksi 3, 6, 9 ja 12 päivän kuluttua kokeen alkamisesta. Rehuista määritettiin 
D-vitamiinipitoisuuksien lisäksi raakavalkuainen, raakarasva, raakakuitu ja tuhka sekä kalsium- ja fosforipitoisuudet.

Kokeen aikana kuolleet ja kokeen päätyttyä tarkoitusta varten lopetetut kanat lähetettiin patologisiin tutkimuksiin Eläinlääkintä- ja elintarviketutkimuslaitokseen. Kanojen ravitsemustila, luuston kunto ja munuaisten, maksan, sydämen, lihasten sekä keuhkojen mahdolliset kalkkeutumat tutkittiin makroskooppisesti. Maksa ja munuaiset tutkittiin lisäksi histologisesti.

Tulokset analysoitiin SAS ohjelmiston GLM proseduurilla. Tuotanto- ja rehunkulutusparametrit analysoitiin toistettujen mittausten varianssianalyysillä käyttäen mallia

$$
\mathrm{Y}_{\mathrm{ijk}}=\mu+\mathrm{d}_{\mathrm{i}}+\mathrm{e}_{\mathrm{ij}}+\mathrm{p}_{\mathrm{k}}+(\mathrm{p} \times \mathrm{d})_{\mathrm{ik}}+\mathrm{e}_{\mathrm{ijk}}
$$

missä $Y_{\mathrm{ijk}}=$ havainto, $\mu=$ yleiskeskiarvo, $\mathrm{d}_{\mathrm{i}}=$ rehun vaikutus $(\mathrm{i}=1, \ldots, 5), \mathrm{p}_{\mathrm{k}}=$ jakson vaikutus $(\mathrm{k}=1, \ldots, 12)$, $\mathrm{e}_{\mathrm{ij}}=$ rehun virhetermi $\mathrm{ja} \mathrm{e}_{\mathrm{ijk}}=$ jakson vaikutuksen virhetermi.

Munanlaatu-, luun murtolujuus-, kasvu- ja kuolleisuustulokset analysoitiin yksisuuntaisella varianssianalyysillä käyttäen mallia

$$
\mathrm{Y}_{\mathrm{ijk}}=\mu+\mathrm{d}_{\mathrm{i}}+\mathrm{e}_{\mathrm{ij}}
$$

missä $Y_{\mathrm{ijk}}=$ havainto, $\mu=$ yleiskeskiarvo, $d_{i}=$ rehun vaikutus $(i=1, \ldots, 5)$ ja $e_{i j}=$ rehun virhetermi. Rehun $\mathrm{D}$-vitamiinilisäysten vaikutuksia vertailtiin lisäksi ortogonaalisin kontrastein.

\section{Tulokset ja tulosten tarkastelu}

Sekä $\mathrm{D}_{2}$ - että $\mathrm{D}_{3}$-vitamiinilisäys nostivat munankeltuaisten $\mathrm{D}$-vitamiinipitoisuutta. $\mathrm{D}_{3}$-vitamiinilisäys näyttäisi kuitenkin soveltuvan paremmin kananmunien D-vitamiinipitoisuuden nostamiseen, sillä $\mathrm{D}_{2^{-}}$ vitamiini ei kerääntynyt kananmunaan yhtä tehokkaasti kuin $\mathrm{D}_{3}$-vitamiini. Lisäksi tuotannon lopussa $\mathrm{D}_{2}$ vitamiinin kertyminen munaan näytti heikkenevän entisestään. Tämän on voinut aiheuttaa rehujen mahdollinen epätasalaatuisuus tai kanan vanhetessa heikentyvä kyky siirtää $\mathrm{D}_{2}$-vitamiinia rehusta muniin.

Munankeltuaisen $\mathrm{D}_{3}$-vitamiinipitoisuus nousi 25,3-31,2 $\mu \mathrm{g}$ :aan 100 grammassa keltuaista, kun rehun $\mathrm{D}_{3}$-vitamiinipitoisuus oli $15000 \mathrm{ky} / \mathrm{kg}$. Kun rehun $\mathrm{D}_{3}$-vitamiinipitoisuus oli $6000 \mathrm{ky} / \mathrm{kg}$, munankeltuaisen $\mathrm{D}_{3}$-vitamiinipitoisuus oli 9,1-13,6 $\mu \mathrm{g} / 100 \mathrm{~g}$ keltuaista. Kananmunien vitamiinitäydennyksen kannalta tämä taso lienee riittävä, sillä yhden munan syöminen täyttäisi 38-56 \% aikuisen suositeltavasta päivittäisestä D-vitamiinin saannista.

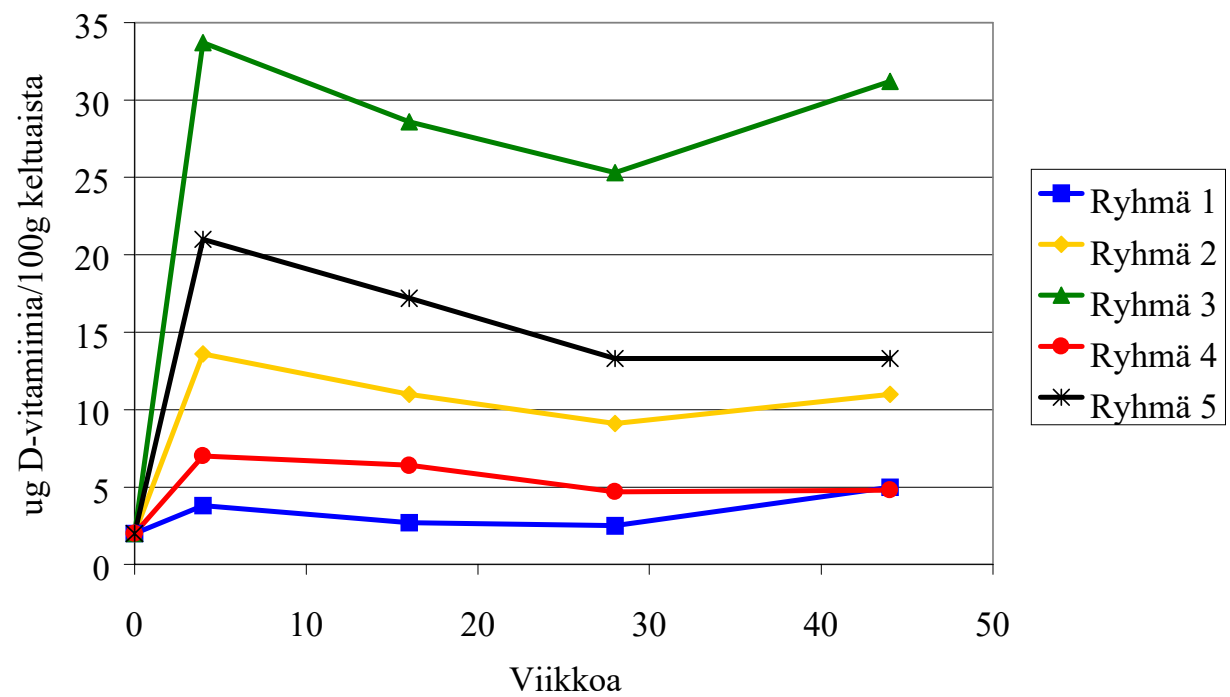

Kuvio 1. Munankeltuaisen D-vitamiinipitoisuus.

D-vitamiinien lisääminen rehuun ei vaikuttanut kanojen tuotantotuloksiin kontrolliryhmään verrattuna. Toisen rehuvaiheen aikana $D_{2}$-vitamiinia saaneiden (ryhmien 4 ja 5) kanojen munintaprosentti oli pienempi kuin $\mathrm{D}_{3}$-vitamiinilisäystä saaneiden (ryhmien 2 ja 3 ) kanojen $(\mathrm{p}=0,021)$. Samansuuntainen trendi havaittiin koko tuotantokautta tarkasteltaessa $(\mathrm{p}=0,061)$. Suuremman D-vitamiinilisän saaneiden (ryhmien 3 ja 5) kanojen munan painot näyttivät olevan hieman pienempiä kuin 6000 ky D-vitamiinia/kg rehua saaneiden (ryhmien 2 ja 4) kanojen munan painot $(p=0,089)$. Päivittäisessä tuotannossa tai munan laadussa ei ryhmien 
välillä ollut eroja. Rehun kulutuksessa, rehunmuuntosuhteessa tai kuolleisuudessa ei myöskään havaittu eroja käsittelyjen välillä.

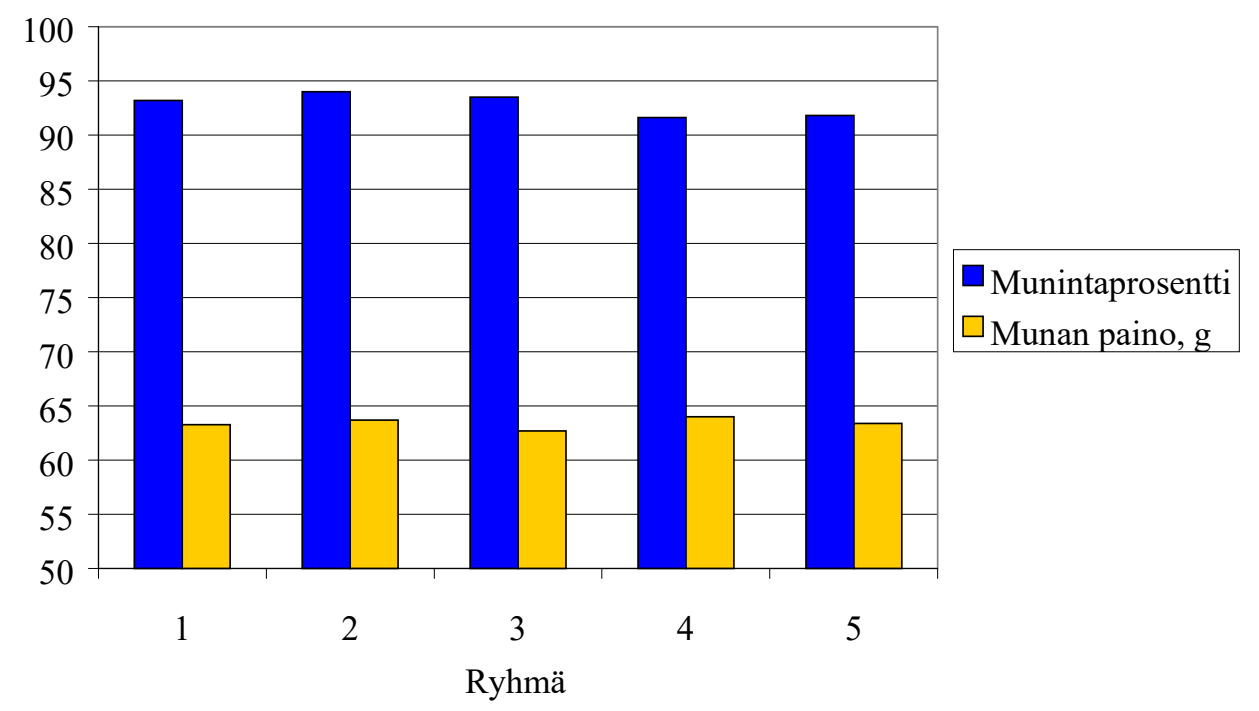

Kuvio 2. Munintaprosentti ja munan paino.

Käsittelyjen välillä oli vain pieniä eroja kanojen painoissa ja kasvuissa. Kanojen sääriluiden murtolujuus sen sijaan oli kontrolliryhmässä merkitsevästi heikompi kuin muissa ryhmissä $(\mathrm{p}=0,016)$. Murtolujuus oli suurin kanoilla, jotka olivat saaneet $\mathrm{D}_{3}$-vitamiinia $15000 \mathrm{ky} / \mathrm{kg}$ rehua. Patologisissa tutkimuksissa ei käsittelyjen välillä havaittu eroja. Sisäelimiin ei ollut syntynyt kalsiumkertymiä.

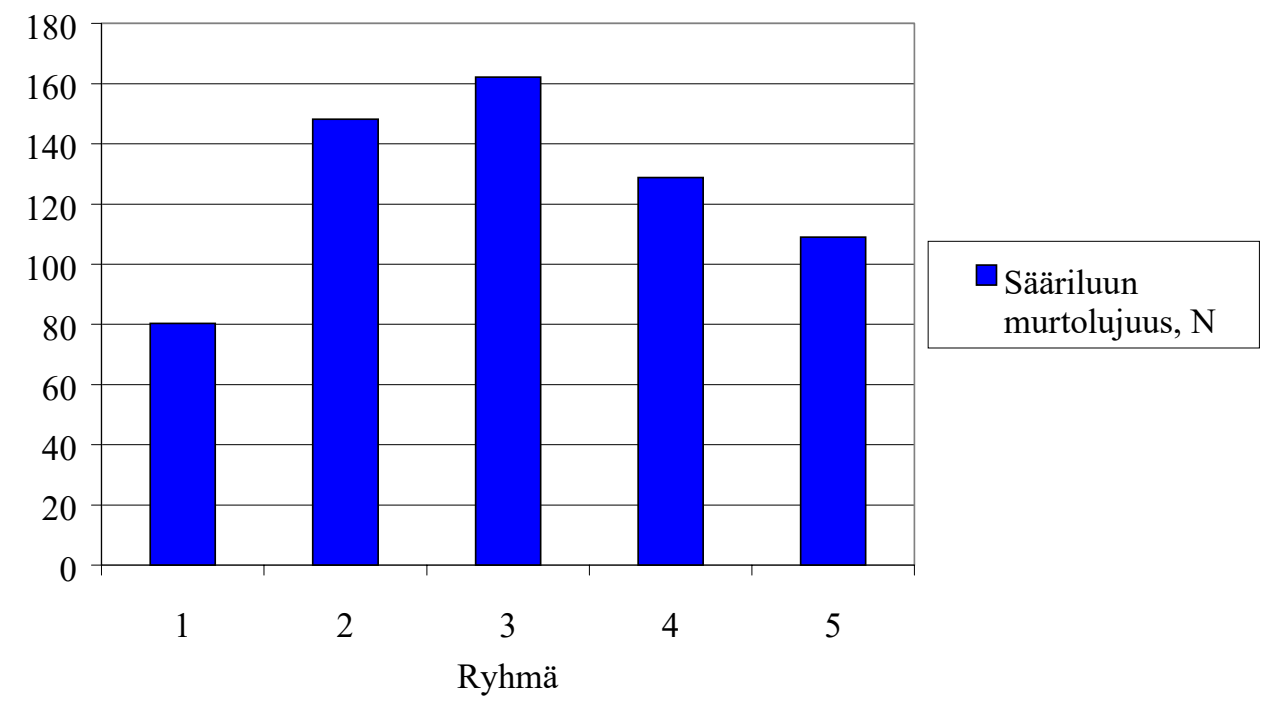

Kuvio 3. Sääriluun murtolujuus.

\section{Johtopäätökset}

$\mathrm{D}_{3}$-vitamiini soveltuu kananmunien vitamiinitäydennykseen paremmin kuin $\mathrm{D}_{2}$-vitamiini. $\mathrm{D}_{2}$-vitamiini ei keräänny kananmunaan yhtä tehokkaasti kuin $\mathrm{D}_{3}$-vitamiini. Rehun $\mathrm{D}_{3}$-vitamiinipitoisuuden nostaminen 6 000:een $\mathrm{ky} / \mathrm{kg}$ rehua nostaa munankeltuaisen $\mathrm{D}_{3}$-vitamiinipitoisuutta jo moninkertaiseksi verrattuna nykyisin käytössä olevaan rehun D-vitamiinipitoisuuteen. Rehun $\mathrm{D}_{3}$-vitamiinipitoisuuden nostamisella ei tässä tutkimuksessa havaittu olevan negatiivisia vaikutuksia kanojen terveyteen tai tuotantoon. $\mathrm{D}_{3^{-}}$ vitamiinilisäys saattaa jopa parantaa kanojen luiden murtolujuutta. 


\section{Kirjallisuus}

Ameenuddin, S., Sunde, M.L. \& Cook, M.E. 1985. Essentiality of vitamin D3 and its metabolites in poultry nutrition: A review. World Poult. Sci. J. 41:52-63.

Mattila, P., Lehikoinen, K., Kiiskinen, T. \& Piironen, V. 1999. Cholecalciferol and 25-hydroxycholecalciferol content of chicken egg yolk as affected by the cholecalciferol content of feed. J. Agric. Food Chem. 47:4089-4092. NRC, 1994. Nutrient Requirements of Poultry, 9th Revised Edition, 1994. Nutritional Research Council, Board on Agriculture, Committee on Animal Nutrition, Subcommittee on Poultry Nutrition. National Academic Press, Washington, DC.

SAS, 1990. SAS/STAT® User's guide, Version 6, $4^{\text {th }}$ Edition, Vols. 1-2. SAS Institute, Cary, NC, 686s.

Scott, M.L., Nesheim, M.C. \&Young, R.J. 1976. Nutrition of the chicken. M.L. Scott \& Associates, Ithaca, New York. 